\title{
Embryonic Development and Adult Regeneration of the Adrenal Gland
}

\author{
Ji-Hoon $\mathrm{Kim}^{1}$, Man Ho Choi ${ }^{2}$ \\ ${ }^{1}$ School of Biological Sciences, Seoul National University; ${ }^{2}$ Molecular Recognition Research Center, Korea Institute of Science \\ and Technology, Seoul, Korea
}

The adrenal gland plays a pivotal role in an organism's health span by controlling the endocrine system. Decades of research on the adrenal gland have provided multiscale insights into the development and maintenance of this essential organ. A particularly interesting finding is that founder stem/progenitor cells participate in adrenocortical development and enable the adult adrenal cortex to regenerate itself in response to hormonal stress and injury. Since major advances have been made in understanding the dynamics of the developmental process and the remarkable regenerative capacity of the adrenal gland, understanding the mechanisms underlying adrenal development, maintenance, and regeneration will be of interest to basic and clinical researchers. Here, we introduce the developmental processes of the adrenal gland and discuss current knowledge regarding stem/progenitor cells that regulate adrenal cortex remodeling and regeneration. This review will provide insights into the fascinating ongoing research on the development and regeneration of the adrenal cortex.

Keywords: Adrenal glands; Adrenal cortex; Developmental biology; Regeneration; Stem cells

\section{INTRODUCTION}

The adrenal gland is a bilateral endocrine organ consisting of the cortex and the medulla, which have different functions and developmental origins [1]. The adrenal cortex synthesizes steroid hormones from cholesterol through a series of biochemical metabolic pathways. The medulla produces epinephrine and norepinephrine as part of the sympathetic nervous system. The cortex develops from mesodermal tissue, whereas the medulla originates from the neuroectoderm [2-4]. The cortex is surrounded by mesenchymal cells that form the adrenal capsule. Underneath the capsule, there are three different cortical zones: the outermost zona glomerulosa $(\mathrm{zG})$, the intermediate zona fasciculate $(\mathrm{zF})$, and the innermost zona reticularis (zR) [1]. Al-

Received: 31 October 2020, Revised: 6 November 2020,

Accepted: 17 November 2020

Corresponding author: Man Ho Choi

Molecular Recognition Research Center, Korea Institute of Science and

Technology, 5 Hwarang-ro 14-gil, Seongbuk-gu, Seoul 02792, Korea

Tel: +82-2-958-5081, Fax: +82-2-958-5059, E-mail: mh_choi@kist.re.kr though many animal models have provided extensive information on the development of the adrenal gland, the origin and regulation of the zonation of the human adrenal cortex remain to be elucidated.

Supported by pools of stem/progenitor cells, the adrenal gland has a high renewal capacity, which allows it to sustain physiological stress and meet hormonal demands [5-7]. In recent decades, exciting discoveries elucidating the identity, function, and fate of these stem/progenitor cell populations have emerged. Based on these findings, embryonic adrenal gland development and adult adrenal gland regeneration were found to share common features in terms of regulatory pathways and transcription factors. Understanding these shared features of adrenal development and regeneration will provide insights into the pathophysi-

Copyright $\odot 2020$ Korean Endocrine Society

This is an Open Access article distributed under the terms of the Creative Commons Attribution Non-Commercial License (https://creativecommons.org/ licenses/by-nc/4.0/) which permits unrestricted non-commercial use, distribution, and reproduction in any medium, provided the original work is properly cited. 
ology of adrenal diseases, as well as regenerative medicine. This review summarizes the overall process of adrenal development and the mechanisms of adrenal regeneration, primarily focusing on adult adrenal stem cells.

\section{DEVELOPMENT OF THE ADRENAL GLAND}

The developmental program of the adrenal gland begins in the embryo and continues in the fetus and postnatal infant (Fig. 1). The adrenal cortex is established from the thickening of the mesoderm-derived coelomic epithelium between the urogenital ridge and the dorsal mesentery during 4 to 6 weeks post-conception in humans and at embryonic day 9 in mice $[1,2,8]$. Clusters of bipotential adrenal gonadal precursors, referred to as the adrenogonadal primordium (AGP), generate both the adrenal cortex and gonads. As the AGP grows along both sides, groups of cells separate from the coelomic epithelium and invade the mesenchymal layer in the intermediate mesoderm. The precursors next to the mesonephros migrate dorsolaterally to form the gonadal primordium, whereas the medial cells that abundantly express steroidogenic factor 1 (steroidogenic factor 1 [SF1], NR5A1, Ad4BP) migrate dorsomedially and converge to establish the adrenal primordium at the cranial pole of the mesonephros $[9,10]$. Thereafter, the cells of the adrenal primordium extensively proliferate and express $17 \alpha$-hydroxylase while the adrenal gland undergoes vascularization $[11,12]$.

During this stage, two dispersed distinct zones are detectable in the adrenal cortex. The fetal zone (FZ) appears in the inner

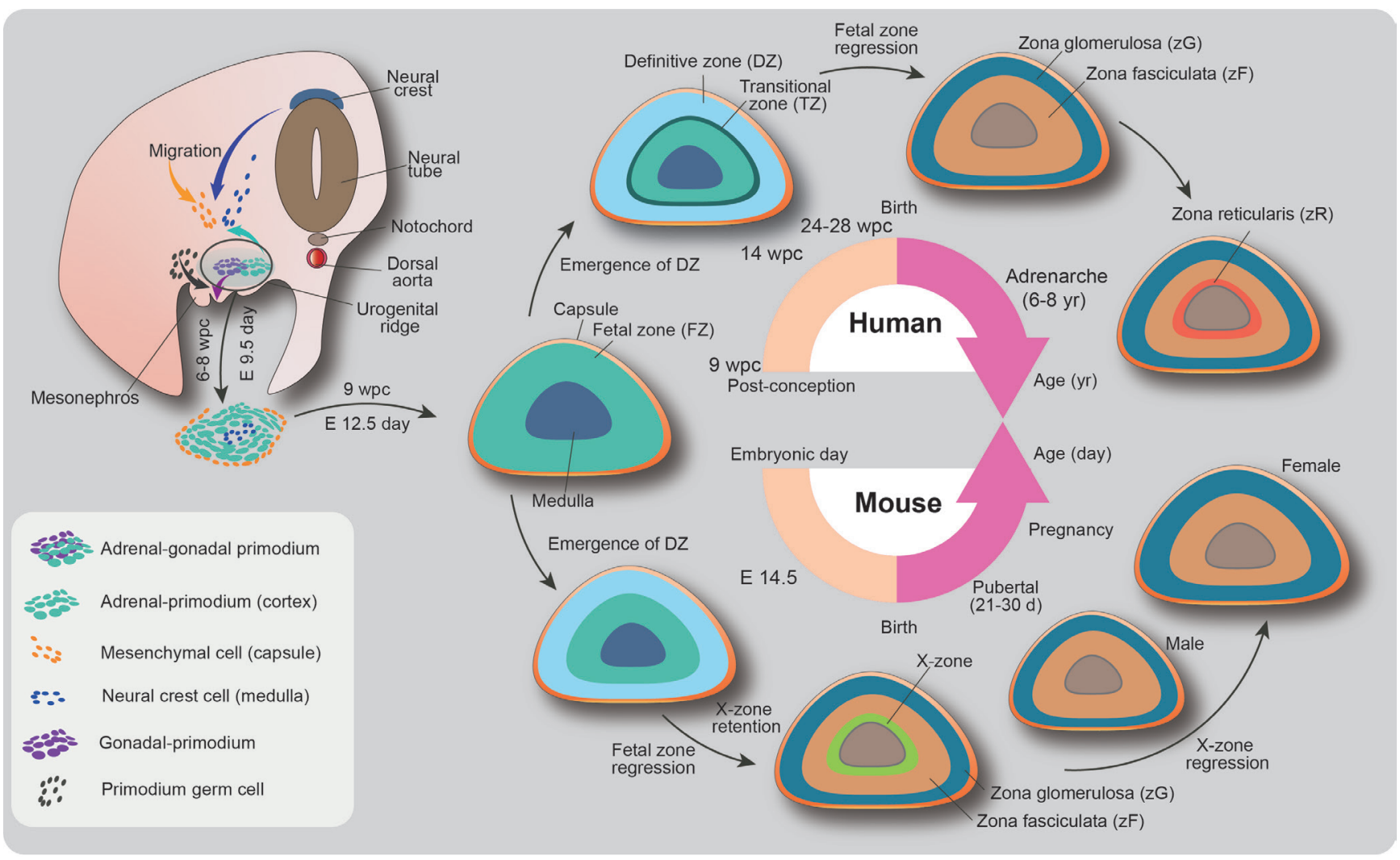

Fig. 1. The establishment of the adrenal gland. In the embryonic stage, following the growth of adrenogonadal primordium (AGP) on both sides, the adrenal progenitor population on the medial side of the AGP and the gonadal progenitor population on the lateral side of the AGP separate to form the adrenal primordium (AP) and the gonadal primordium (GP), respectively. From 6 weeks post-conception (wpc), the neural crest cells that later become the adrenal medulla invade the AP and the mesenchymal cells that become the capsule encapsulate them to establish the fetal adrenal gland. The enlarged fetal zone (FZ) is gradually replaced by the outer definitive zone (DZ). After birth, the FZ regresses through apoptosis and the adrenal cortex starts the zonation of the DZ into the zona glomerulosa (zG) and zona fasciculate (zF). Among the three major cortical zones, the zona reticularis $(\mathrm{zR})$ is the last to develop. At around 6 to 8 years old, a period known as adrenarche, the $\mathrm{zR}$ is formed in the cortical-medullary boundary of the adrenal cortex. The production of adrenal androgens is clearly observed from this stage onwards. Unlike humans, the adrenal cortex in mice exhibits the X-zone as a transient cortical compartment at the corticalmedullary boundary. The regression of the $\mathrm{X}$-zone is sexually dimorphic. 
cortex with high levels of steroidogenic enzymes such as CYP17 and cholesterol side-chain cleavage enzyme (CYP11A), indicating that the fetal adrenal gland synthesizes dehydroepiandrosterone (DHEA) and its sulfated derivative (DHEAS). These steroids serve as sources of placenta-derived $17 \beta$-estradiol. Since the human placenta lacks P450c17 (17 $\alpha$-hydroxylase/17,20lyase) and thus cannot synthesize estrogens de novo from cholesterol, estrogen formation from the DHEAS produced by FZ is essential for maintaining pregnancy $[11,13]$. Simultaneously, the definitive zone (DZ) in the outer cortex expresses relatively low levels of steroidogenic enzymes and emerges with FZ enlargement [13]. This rudimentary fetal adrenal gland is encapsulated by mesenchymal cells until 9 weeks of gestation and embryonic day 12.5 in humans and mice, respectively [3]. The translational zone (TZ) located in the intermediate region between the FZ and DZ is observed 14 weeks post-conception $[11,14,15]$. In the prenatal stage, the TZ produces cortisol via transient expression of $3 \beta$-hydroxysteroid dehydrogenase $/ \Delta^{5}$ $\Delta^{4}$-isomerase (HSD3B2). The cortisol from the TZ is required for the development of various organ systems in utero. The negative regulation of the fetal hypothalamic-pituitary-adrenal (HPA) axis by this early cortisol synthesis plays a role in protecting normal female sexual development by inhibiting the production of adrenal androgens at 8 to 9 weeks post-conception [11].

The cortisol from the cortex also induces the expression of the adrenaline-synthesizing enzyme phenylethanolamine- $N$ methyltransferase in chromaffin cells of the medulla and transcriptionally regulates the expression of chromaffin cell-specific genes and neuron-specific genes [16,17]. The sympathoadrenal primordium, which becomes the adrenal medulla, is induced by the migration of neural crest cells to the dorsal aorta [18]. Neural crest-derived sympathetic cells differentiate into tyrosine hydroxylase-expressing catecholaminergic neuronal progenitor cells in response to bone morphogenetic protein signaling from the surrounding niche [19]. These adrenal medulla precursors move along the nerves and the blood vessels to invade the adrenal primordium and form the adrenal medulla in the innermost region of the adrenal gland. After birth, the medullary islands consist of chromaffin cells within the cortex that coalesce to form a contiguous medulla [20].

\section{ADRENOCORTICAL ZONATION}

Postnatal adrenocortical zonation begins with the differentiation of the fetal adrenal cortex into three major cortical zones (Fig. 1).
The $\mathrm{DZ}$ differentiates into the $\mathrm{zG}, \mathrm{zF}$, and $\mathrm{zR}$. The $\mathrm{zG}$ produces aldosterone, which regulates sodium retention and the intravascular volume via the renin-angiotensin system. The zF produces glucocorticoids associated with glucose metabolism and the immune response, while the zR secretes adrenal androgens. Although the developmental origin and the interplay between the adult cortical zones and the FZs remain to be fully elucidated, considerable efforts in lineage tracing experiments have suggested that the adult cortical zones originate from stem/progenitor cells in the adrenal capsule and the sub-capsular population $[6,21,22]$. In the neonatal stage, the enlarged FZ during gestation rapidly remodels and regresses by apoptosis in the inner region of the FZ, the result of which is the rapid reduction of adrenal androgen secretion after 3 months of birth [23,24]. Subsequently, the zR gradually forms and begins to synthesize androgens again from around age 6 to 8 , a period known as adrenarche in humans [25]. The role of adrenal androgens has not been clearly identified, but interestingly, their secretion profiles decrease with age. Current evidence is limited, but their function may be related to aging of the organism [26,27].

The adrenocortical zones differ among species [4]. In mice, the adrenal cortex has no recognizable $\mathrm{zR}$. The mouse adrenal cortex has the $\mathrm{X}$ zone, a remnant of the fetal adrenal cortex, in contact with the adrenal medulla. The $\mathrm{X}$ zone begins to develop after birth and grows to occupy about $30 \%$ of the cortex. This zone degenerates in male mice at puberty and either at first pregnancy in females or spontaneously in old nulliparous females [28]. The function of the X-zone is thought to be involved in progesterone catabolism [29]. In the rat adrenal cortex, an undifferentiated region $(\mathrm{zU})$ between the $\mathrm{zG}$ and $\mathrm{zF}$ is observed [30]. This zone contributes to adrenal cortical homeostasis and can be divided into two different zones, referred to as the outer $\mathrm{zU}$ and the inner $\mathrm{zU}[30]$. The inner $\mathrm{zU}$ is assumed to be a transitional zone committed to steroidogenesis. Unlike conventional laboratory rodents, the adrenal cortex of spiny mice (Acomys cahirinus) contains the zR and secretes both cortisol and DHEA, similar to the human adrenal cortex, making it a captivating new model for research on adrenal cortex development and disease [31].

\section{RENOVATION AND REMODELING OF ADRENOCORTICAL TISSUE}

In adult homeostasis, the adrenal cortex is responsible for the synthesis of steroid hormones through reciprocal hormonal regulation $[1,4]$. The adrenal cortex spontaneously replenishes dying cells that undergo rapid changes in response to hormonal 
demands for steroid biosynthesis $[6,7,22]$. The adrenocortical stem cell population enables tissue renewal of the adrenal gland and helps to sustain physiological and homeostatic conditions despite constant cellular turnover throughout life (Fig. 2).

To identify bona fide stem cells and critical pathways involved in adrenocortical homeostasis and regeneration, specific lineage tracing and genetic ablation are currently under investigation. Different populations of adrenocortical progenitor cells have been uncovered in the adrenal capsular and sub-capsular region $[3,5,7]$. Similar to other organs, lineage progression in the adult adrenal cortex also proceeds from stem cells (no fate acquired, with self-renewal capacity) to progenitor cells (destiny acquired, with determinant gene activation), and then to ste- roidogenic cells (functional entities). This lineage progression in the adrenal cortex is controlled by the signaling response to both paracrine and endocrine signaling feedback loops, although the detailed mechanism remains to be clarified.

Two models of the adrenocortical renewal process have been proposed: the centripetal hypothesis for different adrenocortical zones, currently accepted $[32,33]$ and the zone-specific hypothesis for lineage dependence, albeit old-fashioned [34]. In the centripetal migration model, undifferentiated progenitor cells in the capsular or sub-capsular region continually produce differentiated zG cells synthesizing mineralocorticoids. These cells migrate centripetally to the inner cortical $\mathrm{zR} /$ medulla boundary. In contrast, the zone-specific model claims that each different
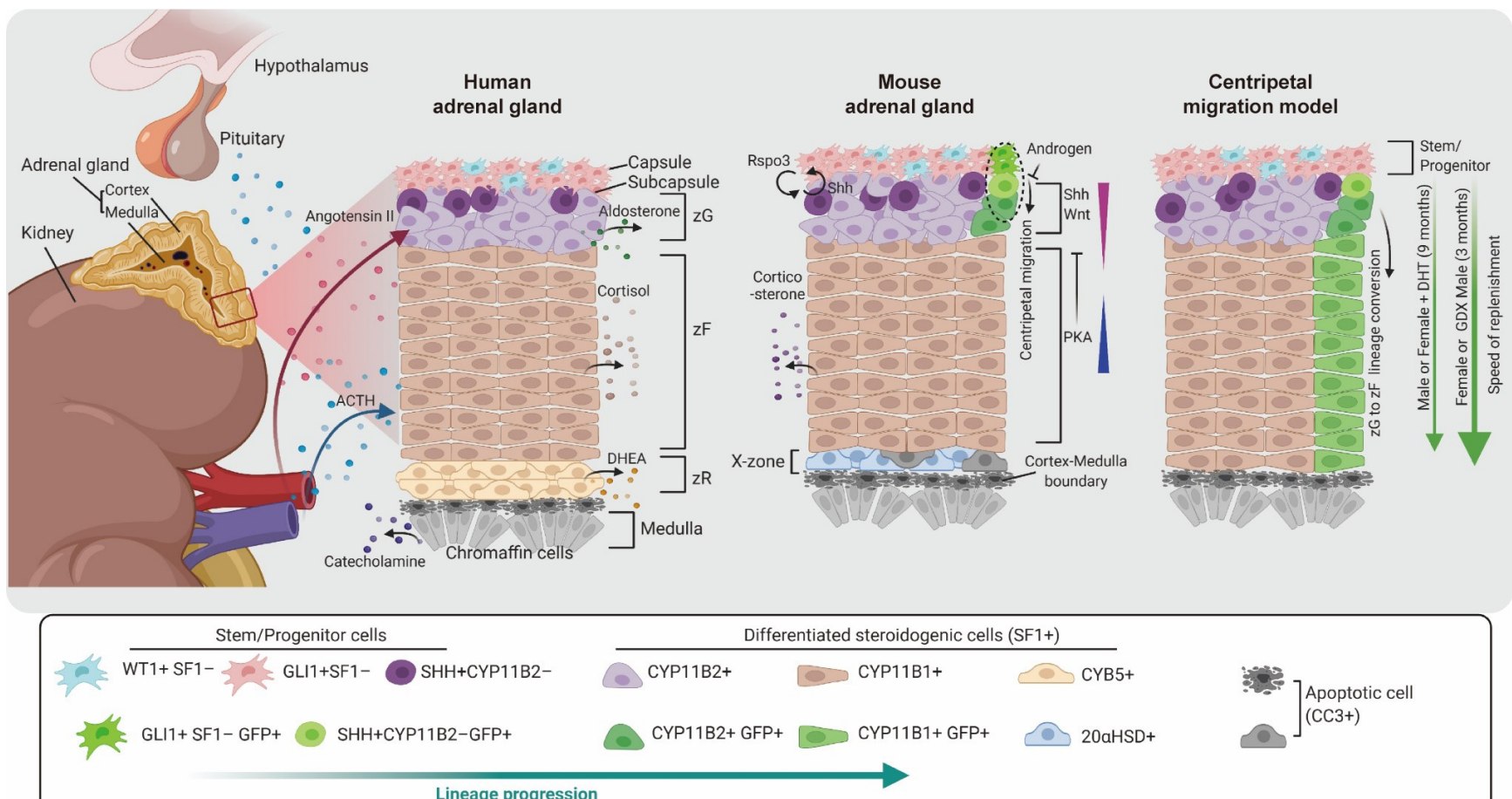

Lineage progression

Fig. 2. Homeostasis, renewal, and regeneration of the adult adrenal cortex. To carry out the unique endocrine functions of the adrenal gland, three major compartments in the adrenal cortex, as well as the medulla, are controlled by external regulatory factors. Under the regulation of the renin-angiotensin system, the zona glomerulosa $(\mathrm{zG})$ produces aldosterone to adjust the levels of sodium and potassium ions in plasma. In response to the circulating adrenocorticotropic hormone (ACTH) from the pituitary gland, the zona fasciculate (zF) and zona reticularis (zR) synthesize cortisol (corticosterone in mice) and adrenal androgens (dehydroepiandrosterone [DHEA] and dehydroepiandrosterone sulfate [DHEAS]), respectively. These steroids are governed by the hypothalamic-pituitary-adrenal (HPA) axis according to hormonal demands and external stress. The adrenocortical stem/progenitor cells in the capsule and sub-capsule regions of the adrenal cortex centripetally replenish senescent steroidogenic cells to maintain healthy steroidogenic cells in the cortical layer. The sonic hedgehog (SHH) and Wnt signaling pathway reciprocally regulate each type of signaling activity, and this mutual relationship is critical for maintaining proper functions of the adrenal cortex. ACTH-protein kinase A (PKA) signaling contributes to differentiating progenitors into steroidogenic cells in the zF. The adrenal cortical regeneration rates in males and females are similar to those of dihydrotestosterone (DHT)-treated females and gonadectomized (GDX) males, respectively, which explains the inhibitory effect of androgens on glioma-associated oncogene homolog 1+ (GLI1+) stem cell recruitment, and sexual dimorphism in the adrenal regeneration [36]. WT1, Wilms' tumor 1; SF1, steroidogenic factor 1; GFP,

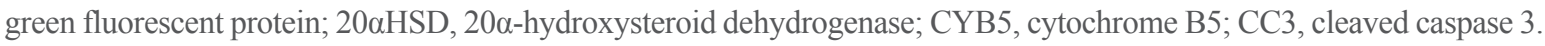


zone is independently maintained by zone-specific progenitor cells, which can give rise to certain zonal cells. A series of prototype experiments have strengthened the centripetal migration hypothesis. The observation of complete adrenal cortex regeneration in an adrenal enucleation experiment, in which the inner content of the adrenal cortex was removed, leaving behind only the capsule and a layer of cells underneath the capsule, provided evidence that the capsular and/or subcapsular compartments in the adrenal cortex contain stem/progenitor cells for inner cortical regions [35]. Moreover, an intravital dye-labeling experiment performed using subcutaneous injections of trypan blue revealed that the initially dye-labeled capsule and zG cells were observed to move into the $\mathrm{zF}$ and eventually were detected in the $\mathrm{zR}$. This finding suggests that newly synthesized cells are derived from the adrenal capsule [32].

In recent, genetic lineage-tracing experiments have provided more direct evidence for the centripetal migration hypothesis. Lineage tracing experiments to monitor the cell fates of sonic hedgehog (SHH)- and glioma-associated oncogene homolog 1 (GLI1)-expressing progenitor cells showed radial stripes that appeared to migrate through the $\mathrm{zG}$ into the $\mathrm{zF}$ [7]. CYP11B2 cell-specific lineage tracing demonstrated that differentiated adrenocortical cells carry out adrenocortical zonation through direct lineage conversion of $\mathrm{zG}$ cells into $\mathrm{zF}$ cells. The lineage conversion of $\mathrm{zG}$ cells into $\mathrm{zF}$ cells also contributes to adrenal cortex regeneration following by dexamethasone-induced damage [6]. Taken together, these two findings reveal that through centripetal migration, $\mathrm{SHH}^{+}$cells, which are descendants of $\mathrm{GLI}^{+}$cells, are major contributors to the replenishment of adrenocortical cells in adult cortical cell renewal and regeneration.

\section{REGULATORY FACTORS INVOLVED IN THE DEVELOPMENT AND RENEWAL OF THE ADRENAL CORTEX}

The adrenal capsule is composed of SF1- mesenchymal cells, which are necessary for maintaining sub-capsular $\mathrm{SF}^{+}$progenitor cells (Fig. 2) [36]. In response to hormonal requirements, $\mathrm{SF}^{-}$capsular stem cells generate sub-capsular $\mathrm{SF}^{+}$progenitors that differentiate into steroidogenic cells within the $\mathrm{zG}$ and $\mathrm{zF}$. Several regulatory factors that are important for the centripetal replenishment of the adrenal cortex have been found. Since the adult renewal and regeneration of the adrenal cortex recapitulate the developmental lineage determination in the embryo, signaling molecules that participate in embryonic adrenal development are often key regulators of adult adrenal cortex homeostasis.

\section{Hedgehog pathway}

$\mathrm{SHH}$, a hedgehog family ligand, is secreted by subcapsular cells that express SF1, but not steroidogenic enzymes such as CYP11B1 and CYP11B2 [7,37,38]. The related transcriptional effector, GLI1, is upregulated by the activation of the SHH pathway, and the GLII gene thus serves as a marker of hedgehog signaling activation [39]. Capsular cells that express GLI1 in response to SHH from subcapsular cells migrate centripetally into the cortex and differentiate into steroidogenic cells with a distinct zone-specific marker of the $\mathrm{zG}$ (CYP11B2) or zF (CYP11B1). GLI1 ${ }^{+}$progenitor cells are also responsible for differentiation into steroidogenic lineage cells during the cortical development in embryo, fetus, and newborn mice [7]. Moreover, it has been reported that the SHH pathway plays a critical role in adult adrenal regeneration. Following dexamethasone-induced atrophy, constitutively activating SHH signaling in capsular cells enhances adrenal cortex regeneration, whereas pharmacological inhibition of Shh signaling reduces the regeneration capacity. Mechanistically, the constitutive activation of SHH signaling is correlated with Wnt signaling activity, a pathway that is activated in the cortex during the regeneration process [40]. Taken together, these studies show not only the potential role of SHH-expressing cells as a stem/progenitor population for adrenal cortex homeostasis, but also the necessity of SHH signaling for adrenocortical regeneration.

\section{WNT pathway}

The canonical Wnt signaling pathway is responsible for both the embryonic establishment and homeostatic maintenance of the adrenal cortex. Mouse models of Wnt signaling ablation in steroidogenic cells have shown that Wnt signaling is critical for adrenocortical maintenance in both embryonic and adult mouse adrenal glands [21]. Among the Wnt signaling ligands, Wnt4 is produced by cells located in the subcapsular/zG region in mice, and it appears to be involved in adrenocortical homeostasis via the canonical Wnt signaling pathway. Homozygous loss of Wnt4 in mice results in postnatal adrenal defects, suggesting that Wnt4 plays an important role in neonatal zonation and steroidogenesis [41]. In humans, a homozygous mutation in WNT4 was found to result in severe developmental defects, including adrenal hypoplasia [42].

Interesting evidence regarding the regulation of Wnt signaling in both the establishment of adrenocortical zonation and in the maintenance of the capsular stem/progenitor cell niche has recently been reported. SF $1^{-}$capsular stem cells secrete $\mathrm{R}$-spondin 3 (Rspo3) to induce Wnt/ $\beta$-catenin signaling activation in 
the underlying steroidogenic compartment, and impaired expression of Rspo3 in capsular progenitors reduces Shh and Wnt4 expression in zG cells [43]. These results indicate that reciprocal inter-compartmental signaling maintains the $\mathrm{zG}$ characteristics and adrenal homeostasis through a cooperative mechanism.

\section{ACTH/PKA signaling}

The production of cortisol and androgen in humans (corticosterone in mice) by adrenocortical steroidogenic cells is governed by the HPA axis. Adrenocorticotropic hormone (ACTH) from the pituitary gland stimulates cortisol production from the adrenal $\mathrm{zF}$ by activating cAMP-dependent protein kinase A (PKA) signaling $[44,45]$. The complex of melanocortin 2 receptor (MC2R) and its accessory protein (MRAP) on the surface of adrenocortical cells plays an essential role in mediating the action of pituitary ACTH and subsequent steroidogenesis [46,47]. MRAP deficiency was found to lead to neonatal lethality in mice, and the administration of exogenous glucocorticoids rescued the lethality. However, the MRAP-deficient mice rescued by glucocorticoid treatment showed impaired steroidogenesis due to an accumulation of progenitor cells from activated $\mathrm{SHH}$ and Wnt signaling [48]. These results explain why ACTH signaling via PKA induces the differentiation of adrenocortical stem/progenitor cells into steroidogenic cells of the $\mathrm{zF}$.

\section{Regulation of SF1 transcriptional activity}

SF1 is a major transcription factor involved in adrenal development and function. Forced expression of SF1 in adipose-derived and bone marrow-derived mesenchymal cells [49-52], as well as in mouse embryonic stem cells [51,53], induces their differentiation into steroidogenic cells. Moreover, transgenic mice that expressed SF1 under the control of fetal adrenal enhancer showed increased adrenal size and the formation of ectopic adrenal tissue in the thorax [54]. These results indicate that the forced expression of SF1 causes the switch of nonadrenal lineage cells to the adrenal cell fate. The activation of SF1 expression and modulation of SF1-dependent transcription have been found to play an important role in these phenomena. Both oddskipped related 1 [55] and Sal-like 1 (SALL1) [56] deletion cause reduced expression of Wilms' tumor protein 1 (WT1). WT1 binds to the promoter region within the SF1 gene and cooperates with the coactivator $\mathrm{Cbp} / \mathrm{p} 300$-interacting transactivator 2. This complex strongly induces SF1 expression, which is required for adrenal primordium development [57]. Furthermore, to adjust to the differentiation to steroidogenic cells, SF1 self-inhibits its transcriptional activity by activating DAX1, the repressor of SF1 [58]. These findings indicate that fine control of SF1 transcriptional activity is required for proper adrenal development.

\section{CONCLUSIONS}

The signaling pathways that regulate the formation of the adrenal cortex in the embryo are shared in the regeneration process that occurs in response to hormonal demand and surgical damage. Several animal experiments have shown that the regulatory genes involved in adrenal cortical stem/progenitor cell identity, fate, and differentiation during development are also necessary during the adult adrenal regeneration process. However, the regulatory network in the human adrenal gland remains to be validated. Thus, the unraveling of the undefined gene regulatory network between human adrenal cortical development and regeneration will be a topic of major interest.

Despite the remaining challenges, human organoids and single-cell RNA sequencing techniques based on epigenetic modulation have provided great potential in translational studies $[59,60]$. Technological advances in both approaches may elucidate aspects of human biology relevant for research on the adrenal glands and pathological processes therein. As the establishment of many organoid systems has gained insights from the understanding of organogenesis, current and future knowledge on adrenal development and regeneration will lay the foundation for the development of human adrenal organoid systems.

\section{CONFLICTS OF INTEREST}

No potential conflict of interest relevant to this article was reported.

\section{ACKNOWLEDGMENTS}

This study was supported by a grant from the Korea Institute of Science and Technology Institutional Program (Project No. 2E30480), and the National Research Foundation of Korea (NRF-2020R1A2C2101897) through the Ministry of Science and ICT.

\section{ORCID}

Ji-Hoon Kim https://orcid.org/0000-0002-9217-4483

Man Ho Choi https://orcid.org/0000-0003-1017-1156 


\section{REFERENCES}

1. Yates R, Katugampola H, Cavlan D, Cogger K, Meimaridou E, Hughes C, et al. Adrenocortical development, maintenance, and disease. Curr Top Dev Biol 2013;106:239-312.

2. Ross IL, Louw GJ. Embryological and molecular development of the adrenal glands. Clin Anat 2015;28:235-42.

3. Walczak EM, Hammer GD. Regulation of the adrenocortical stem cell niche: implications for disease. Nat Rev Endocrinol 2015;11:14-28.

4. Pihlajoki M, Dorner J, Cochran RS, Heikinheimo M, Wilson DB. Adrenocortical zonation, renewal, and remodeling. Front Endocrinol (Lausanne) 2015;6:27.

5. Finco I, Mohan DR, Hammer GD, Lerario AM. Regulation of stem and progenitor cells in the adrenal cortex. Curr Opin Endocr Metab Res 2019;8:66-71.

6. Freedman BD, Kempna PB, Carlone DL, Shah M, Guagliardo NA, Barrett PQ, et al. Adrenocortical zonation results from lineage conversion of differentiated zona glomerulosa cells. Dev Cell 2013;26:666-73.

7. King P, Paul A, Laufer E. Shh signaling regulates adrenocortical development and identifies progenitors of steroidogenic lineages. Proc Natl Acad Sci U S A 2009;106:21185-90.

8. Else T, Hammer GD. Genetic analysis of adrenal absence: agenesis and aplasia. Trends Endocrinol Metab 2005;16:45868.

9. Luo X, Ikeda Y, Parker KL. A cell-specific nuclear receptor is essential for adrenal and gonadal development and sexual differentiation. Cell 1994;77:481-90.

10. Kim AC, Barlaskar FM, Heaton JH, Else T, Kelly VR, Krill $\mathrm{KT}$, et al. In search of adrenocortical stem and progenitor cells. Endocr Rev 2009;30:241-63.

11. Goto M, Piper Hanley K, Marcos J, Wood PJ, Wright S, Postle $\mathrm{AD}$, et al. In humans, early cortisol biosynthesis provides a mechanism to safeguard female sexual development. J Clin Invest 2006;116:953-60.

12. Hanley NA, Rainey WE, Wilson DI, Ball SG, Parker KL. Expression profiles of SF-1, DAX1, and CYP17 in the human fetal adrenal gland: potential interactions in gene regulation. Mol Endocrinol 2001;15:57-68.

13. Mesiano S, Jaffe RB. Developmental and functional biology of the primate fetal adrenal cortex. Endocr Rev 1997;18:378403.

14. Mesiano S, Coulter CL, Jaffe RB. Localization of cytochrome P450 cholesterol side-chain cleavage, cytochrome P450 17 alpha-hydroxylase/17, 20-lyase, and 3 beta-hydroxysteroid dehydrogenase isomerase steroidogenic enzymes in human and rhesus monkey fetal adrenal glands: reappraisal of functional zonation. J Clin Endocrinol Metab 1993;77:1184-9.

15. Ishimoto $H$, Jaffe RB. Development and function of the human fetal adrenal cortex: a key component in the feto-placental unit. Endocr Rev 2011;32:317-55.

16. Michelsohn AM, Anderson DJ. Changes in competence determine the timing of two sequential glucocorticoid effects on sympathoadrenal progenitors. Neuron 1992;8:589-604.

17. Yoshida-Hiroi M, Bradbury MJ, Eisenhofer G, Hiroi N, Vale WW, Novotny GE, et al. Chromaffin cell function and structure is impaired in corticotropin-releasing hormone receptor type 1-null mice. Mol Psychiatry 2002;7:967-74.

18. Anderson DJ, Carnahan JF, Michelsohn A, Patterson PH. Antibody markers identify a common progenitor to sympathetic neurons and chromaffin cells in vivo and reveal the timing of commitment to neuronal differentiation in the sympathoadrenal lineage. J Neurosci 1991;11:3507-19.

19. Reissmann E, Ernsberger U, Francis-West PH, Rueger D, Brickell PM, Rohrer H. Involvement of bone morphogenetic protein- 4 and bone morphogenetic protein-7 in the differentiation of the adrenergic phenotype in developing sympathetic neurons. Development 1996;122:2079-88.

20. Wilburn LA, Goldsmith PC, Chang KJ, Jaffe RB. Ontogeny of enkephalin and catecholamine-synthesizing enzymes in the primate fetal adrenal medulla. J Clin Endocrinol Metab 1986;63:974-80.

21. Kim AC, Reuter AL, Zubair M, Else T, Serecky K, Bingham NC, et al. Targeted disruption of beta-catenin in Sf1-expressing cells impairs development and maintenance of the adrenal cortex. Development 2008;135:2593-602.

22. Wood MA, Acharya A, Finco I, Swonger JM, Elston MJ, Tallquist MD, et al. Fetal adrenal capsular cells serve as progenitor cells for steroidogenic and stromal adrenocortical cell lineages in M. musculus. Development 2013;140:4522-32.

23. Wiener D, Smith J, Dahlem S, Berg G, Moshang T Jr. Serum adrenal steroid levels in healthy full-term 3-day-old infants. J Pediatr 1987;110:122-4.

24. Kojima S, Yanaihara T, Nakayama T. Serum steroid levels in children at birth and in early neonatal period. Am J Obstet Gynecol 1981;140:961-5.

25. Nakamura Y, Gang HX, Suzuki T, Sasano H, Rainey WE. Adrenal changes associated with adrenarche. Rev Endocr Metab Disord 2009;10:19-26.

26. Jia X, Sun C, Tang O, Gorlov I, Nambi V, Virani SS, et al. Plasma dehydroepiandrosterone sulfate and cardiovascular 
disease risk in older men and women. J Clin Endocrinol Metab 2020;105:dgaa518.

27. Rendina DN, Ryff CD, Coe CL. Precipitous dehydroepiandrosterone declines reflect decreased physical vitality and function. J Gerontol A Biol Sci Med Sci 2017;72:747-53.

28. Howard-Miller E. A transitory zone in the adrenal cortex which shows age and sex relationships. Am J Anat 1927;40: 251-93.

29. Hershkovitz L, Beuschlein F, Klammer S, Krup M, Weinstein Y. Adrenal 20alpha-hydroxysteroid dehydrogenase in the mouse catabolizes progesterone and 11-deoxycorticosterone and is restricted to the X-zone. Endocrinology 2007;148:97688.

30. Guasti L, Cavlan D, Cogger K, Banu Z, Shakur A, Latif S, et al. Dlk1 up-regulates Gli1 expression in male rat adrenal capsule cells through the activation of $\beta 1$ integrin and ERK1/2. Endocrinology 2013;154:4675-84.

31. Quinn TA, Ratnayake U, Dickinson H, Nguyen TH, McIntosh M, Castillo-Melendez M, et al. Ontogeny of the adrenal gland in the spiny mouse, with particular reference to production of the steroids cortisol and dehydroepiandrosterone. Endocrinology 2013;154:1190-201.

32. Salmon TN, Zwemer RL. A study of the life history of cortico-adrenal gland cells of the rat by means of trypan blue injections. Anat Rec 1941;80:421-9.

33. Zwemer RL, Wotton RM, Norkus MG. A study of corticoadrenal cells. Anat Rec 1938;72:249-63.

34. Deane HW, Greep RO. A morphological and histochemical study of the rat's adrenal cortex after hypoph ysectomy, with comments on the liver. Am J Anat 1946;79:117-45.

35. Ingle DJ, Higgins GM. The extent of regeneration of the enucleated adrenal gland in the rat as influenced by the amount of capsule left at operation. Endocrinology 1939;24:379-82.

36. Grabek A, Dolfi B, Klein B, Jian-Motamedi F, Chaboissier MC, Schedl A. The adult adrenal cortex undergoes rapid tissue renewal in a sex-specific manner. Cell Stem Cell 2019;25: 290-6.

37. Ching S, Vilain E. Targeted disruption of Sonic Hedgehog in the mouse adrenal leads to adrenocortical hypoplasia. Genesis 2009;47:628-37.

38. Huang CC, Miyagawa S, Matsumaru D, Parker KL, Yao HH. Progenitor cell expansion and organ size of mouse adrenal is regulated by sonic hedgehog. Endocrinology 2010;151:111928.

39. Vokes SA, Ji H, McCuine S, Tenzen T, Giles S, Zhong S, et al. Genomic characterization of Gli-activator targets in sonic hedgehog-mediated neural patterning. Development 2007; 134:1977-89.

40. Finco I, Lerario AM, Hammer GD. Sonic hedgehog and WNT signaling promote adrenal gland regeneration in male mice. Endocrinology 2018;159:579-96.

41. Heikkila M, Peltoketo H, Leppaluoto J, Ilves M, Vuolteenaho O, Vainio S. Wnt-4 deficiency alters mouse adrenal cortex function, reducing aldosterone production. Endocrinology 2002;143:4358-65.

42. Mandel H, Shemer R, Borochowitz ZU, Okopnik M, Knopf $\mathrm{C}$, Indelman M, et al. SERKAL syndrome: an autosomal-recessive disorder caused by a loss-of-function mutation in WNT4. Am J Hum Genet 2008;82:39-47.

43. Vidal V, Sacco S, Rocha AS, da Silva F, Panzolini C, Dumontet $\mathrm{T}$, et al. The adrenal capsule is a signaling center controlling cell renewal and zonation through Rspo3. Genes Dev 2016;30:1389-94.

44. Lotfi CF, de Mendonca PO. Comparative effect of ACTH and related peptides on proliferation and growth of rat adrenal gland. Front Endocrinol (Lausanne) 2016;7:39.

45. Clark BJ. ACTH action on StAR biology. Front Neurosci 2016;10:547.

46. Hofland J, Delhanty PJ, Steenbergen J, Hofland LJ, van Koetsveld PM, van Nederveen FH, et al. Melanocortin 2 receptor-associated protein (MRAP) and MRAP2 in human adrenocortical tissues: regulation of expression and association with ACTH responsiveness. J Clin Endocrinol Metab 2012; 97:E747-54.

47. Clark AJL, Chan L. Stability and turnover of the ACTH receptor complex. Front Endocrinol (Lausanne) 2019;10:491.

48. Novoselova TV, Hussain M, King PJ, Guasti L, Metherell LA, Charalambous M, et al. MRAP deficiency impairs adrenal progenitor cell differentiation and gland zonation. FASEB J 2018;32:fj201701274RR.

49. Gondo S, Yanase T, Okabe T, Tanaka T, Morinaga H, Nomura $\mathrm{M}$, et al. SF-1/Ad4BP transforms primary long-term cultured bone marrow cells into ACTH-responsive steroidogenic cells. Genes Cells 2004;9:1239-47.

50. Yazawa T, Mizutani T, Yamada K, Kawata H, Sekiguchi T, Yoshino M, et al. Differentiation of adult stem cells derived from bone marrow stroma into Leydig or adrenocortical cells. Endocrinology 2006;147:4104-11.

51. Yazawa T, Kawabe S, Inaoka Y, Okada R, Mizutani T, Imamichi $Y$, et al. Differentiation of mesenchymal stem cells and embryonic stem cells into steroidogenic cells using steroidogenic factor-1 and liver receptor homolog-1. Mol Cell 
Endocrinol 2011;336:127-32.

52. Gondo S, Okabe T, Tanaka T, Morinaga H, Nomura M, Takayanagi R, et al. Adipose tissue-derived and bone marrow-derived mesenchymal cells develop into different lineage of steroidogenic cells by forced expression of steroidogenic factor 1. Endocrinology 2008;149:4717-25.

53. Crawford PA, Sadovsky Y, Milbrandt J. Nuclear receptor steroidogenic factor 1 directs embryonic stem cells toward the steroidogenic lineage. Mol Cell Biol 1997;17:3997-4006.

54. Zubair M, Oka S, Parker KL, Morohashi K. Transgenic expression of Ad4BP/SF-1 in fetal adrenal progenitor cells leads to ectopic adrenal formation. Mol Endocrinol 2009;23:165767.

55. Wang Q, Lan Y, Cho ES, Maltby KM, Jiang R. Odd-skipped related 1 (Odd 1) is an essential regulator of heart and urogenital development. Dev Biol 2005;288:582-94.

56. Nishinakamura R, Matsumoto Y, Nakao K, Nakamura K,
Sato A, Copeland NG, et al. Murine homolog of SALL1 is essential for ureteric bud invasion in kidney development. Development 2001;128:3105-15.

57. Val P, Martinez-Barbera JP, Swain A. Adrenal development is initiated by Cited 2 and $\mathrm{Wt} 1$ through modulation of Sf- 1 dosage. Development 2007;134:2349-58.

58. Clipsham R, Niakan K, McCabe ER. Nr0b1 and its network partners are expressed early in murine embryos prior to steroidogenic axis organogenesis. Gene Expr Patterns 2004;4:314.

59. Kim J, Koo BK, Knoblich JA. Human organoids: model systems for human biology and medicine. Nat Rev Mol Cell Biol 2020;21:571-84.

60. Ho BX, Pek NMQ, Soh BS. Disease modeling using 3D organoids derived from human induced pluripotent stem cells. Int J Mol Sci 2018;19:936. 